\title{
PERBEDAAN KECENDERUNGAN DEPRESI POSTPARTUM (DPP) PADA PERSALINAN SEKSIO SESARIA DAN PERSALINAN SPONTAN DI RSUD NENE MALLOMO KABUPATEN SIDRAP
}

\author{
"Wilda Rezki Pratiwi, Syahriani \\ *Prodi DIII Kebidanan, STIKES Muhammadiyah Sidrap, email: wildapratiwi06@gmail.com
}

\begin{tabular}{l} 
INFO ARTIKEL \\
\hline Riwayat Artikel: \\
Diterima: $23-06-2019$ \\
Disetujui: $11-07-2019$
\end{tabular}

Kata Kunci:

Depresi Potpartum(DPM)

Seksio sesaria

Spontan

\begin{abstract}
ABSTRAK
Abstrak: Postpartum depression (PPD) atau depresi pascamelahirkan merupakan masalah kesehatan dalam masyarakat modern. Kehamilan dan melahirkan merupakan periode kehidupan yang cenderung mengalami stres. Pada periode tersebut dapat menyebabkan suatu perubahan besar melibatkan peningkatan gejolak fisik dan emosional. Tujuan penelitian ini untuk menganalisa kecenderungan depresi postpartum dari jenis persalinan dan mendapatkan hasil yang dapat mempengaruhi kecenderungan mengalami depresi postpartum. Desain penelitian yang digunakan adalah desain survey analitik dengan pendekatan cross sectional study yang bertujuan untuk mengetahui perbedaan kecenderungan depresi postpartum pada persalinan seksio sesaria dan persalinan spontan. Populasi 87 orang. Sampel dalam penelitian ini berjumlah 40 ibu post partum. 20 orang melahirkan dengan Normal dan 20 orang yang melahirkan secara Seksio sesar di RSUD Nene Mallomo Kabupaten Sidrap. Partisipan direkrut menggunakan teknik purposive sampling. Hasil penelitian menunjukan hasil analisis Mann Whitney $U$ test menunjukan jenis persalinan $p$ value $0,212(p>0,05)$ tidak ada perbedaan jenis persalinan terhadap kecendrungan depresi post partum, dukungan suami menunjukan $p$ value $0,000(p<0,05)$ artinya ada perbedaan dukungan suami terhadap kecendrungan depresi post partum. Dukungan keluarga menunjukan $p$ value 0,152 ( $p>0,05)$ artinya tidak ada perbedaan dukungan keluarga terhadap kecendrungan depresi post partum. Diharapkan dukungan suami dimulai dari kehamilan, persalinan dan nifas sehingga memberikan kemampuan yang lebih kepada wanita dalam menghadapi stres yang muncul dan wanita tersebut dapat terhindar dari depresi pasca postpartum.
\end{abstract}

\begin{abstract}
Postpartum depression (PPD) is a health problem in modern society. Pregnancy and childbirth are periods of life when women tend to experience overwhelming stress. This period alsomaylead to a major change involving an increased physical and emotional distress. The study aimed to analyze the tendency of postpartum depression from the labor type and discover the results that can affect the tendency to experience postpartum depression. The research design used an analytical survey design with a cross-sectional analytic approach which aims to determine the differences in postpartum depression tendencies in cesarean delivery (c-section) and spontaneous labor. 87 people participated in this study. The sample are 40 postpartum mothers,20 people who gave birth by normal delivery, and 20 people who gave birth through Sectio Secaria in Nene Mallomo District Hospital, Sidrap. participants were recruited by using a purposive sampling technique. The results indicated that Mann Whitney $U$ test analysis is the labour type of pvalue 0.212 ( $p>$ $0.05)$ was no differences in the labor type towards postpartum depression tendencies, husband's support showspvalue 0.000 ( $p<0.05)$ means that there were differences in husband's support towards postpartum depression. Family's support shows pvalue of 0.152 ( $p>0.05$ ) means that there is no differences in family's support toward postpartum depression tendencies. Husband's support expected to begin early from pregnancy, childbirth and parturition so as to provide more support for women to deal with stress arises after birth delivery and may be able to avoid postpostpartum depression.
\end{abstract}

\section{A. LATAR BELAKANG}

Postpartum depression (PPD) merupakan masalah kesehatan dalam masyarakat modern. Prevalensinya berkisar antara $7.6 \%$ sampai $39 \%$ di

berbagai wilayah di dunia dan berbeda menurut populasi yang diuji dan alat skrining yang digunakan ${ }^{[1]}$.

Dalam Centre for Maternal and Child Enquiries [2], $59 \%$ dari kasus bunuh diri ibu karena psikosis. Namun
$76 \%$ dari perempuan yang telah menikah atau hidup di lingkungan yang kehidupannya statis. Berdasarkan Laporan WHO diperkirakan wanita melahirkan yang mengalami depresi postpartum (DPP) ringan berkisar 10 per 1000 kelahiran hidup $(\mathrm{KH})$ dan depresi postpartum sedang atau berat berkisar 30 sampai 200 per $1000 \mathrm{KH}$ [4]. Angka kejadian DPP di Asia cukup tinggi dan sangat bervariasi antara $26-85 \%$, sedangkan di Indonesia angka kejadian DPP antara 50-70\% 
postpartum [5]. Berdasarkan hasil dari Centers for Disease Control and Prevention (CDC) prevalensi DPP berkisar antara $11.7 \%$ sampai $20.4 \%$ pada tahun 2004$2005^{[4]}$.

Di Indonesia sendiri BKKBN Provinsi Aceh tahun 2012 menemukan 7 dari $10 \mathrm{ibu}$ yang melahirkan DPP dengan gejala tidak ada nafsu makan dan susah tidur. Yogyakarta dan Surabaya didapatkan angka kejadian DPP sebesar 15 - $20 \%$. Jakarta menemukan angka kejadian DPP sebesar 11-30\% ibu yang mengalami DPP.

Berdasarkan hasil Survey Dasar Kesehatan Indonesia (SDKI) tahun 2012 indikator angka kematian bayi (AKB) hanya turun sedikit dari pencapaian tahun 2007, yaitu dari 32 per 1.000 kelahiran hidup menjadi 32 per 1.000 kelahiran hidup. Tahun 2012 menunjukkan AKB berada pada angka 32 per 1.000 kelahiran hidup turun lima point dari tahun 2001.

Pentingnya memahami DPP karena berpotensi menimbulkan kematian bayi dan ibunya. Perubahan mood atau perasaan postpartum bukanlah masalah yang mudah ditangani, akan tetapi dampaknya dapat merusak kehidupan ibu, keluarga, bayi dan anakanaknya karena komplikasi yang diakibatkan. Ibu akan mengalami kesulitan dalam melakukan perannya sebagai ibu, dan menjalin ikatan emosional terhadap bayi maupun anaknya. Berbagai dampak yang akan dialami anak dan ibu, diantaranya dampak bagi anaknya dapat mengalami gangguan emosional dan perilaku, keterlambatan bahasa dan gangguan kognitif dan bagi ibu tersebut akan merasa dalam kondisi yang berat sehingga timbul keinginan untuk mengakhiri penderitaannya dan anaknya [6,7].

Sebagaimana fenomena yang terjadi dimasyarakat banyak seorang ibu membunuh bayinya sendiri seperti yang terjadi "di Tanah Toraja Ny M (43 tahun), setelah melahirkan tega membunuh bayinya" [8]. Dan "Ny A, Gowa Sulawesi Selatan, tega membunuh bayinya karena alasan sepele" [9]. Dan masih banyak lagi fenomena ibu melukai bahkan membunuh bayinya yang terjadi di Sulawesi Selatan maupun diluar Sulawesi Selatan. Untuk itu sehingga penulis ingin Menganalisa perbedaan depresi postpartum pada riwayat persalinan seksio sesaria dan persalinan spontan di RSUD Nene Mallomo Kabupaten Sidrap.

\section{B. METODE PENELITIAN}

Desain penelitian yang digunakan adalah desain survey analitik dengan pendekatan cross sectional study yang bertujuan untuk mengetahui perbedaan kecenderungan depresi postpartum pada persalinan seksio sesaria dan persalinan spontan. Instrument pengumpulan data dalam penelitian ini adalah kuisioner EPDS (Edinburgh Postnatal Depression Scale)

Partisipan direkrut menggunakan teknik purposive sampling. Sampel dalam penelitian ini berjumlah 40 ibu post partum. 20 orang melahirkan dengan Normal dan 20 orang yang melahirkan secara Sectio Secaria di RSUD Nene Mallomo Kabupaten Sidrap.

Partisipan dipilih jika memenuhi kriteria inklusi berikut: a) Ibu riwayat persalinan seksio sesaria b) Ibu riwayat persalinan spontan, c) Kesediaan untuk mematuhi protokol penelitian d) Usia kehamilan aterm (38 - 42 minggu). Kriteria ekslusi meliputi: a) Ibu memiliki komplikasi postpartum, b) Ibu yang melahirkan bayi dengan bblr (bayi berat lahir rendah) c) Ibu hamil yang suaminya meninggal. Analisis dalam penelitian ini menggunakan uji sesuai tujuan dan skala ukur variabel yaitu Mann Whitney U test.

\section{HASIL DAN PEMBAHASAN}

\section{Analisis Univariat}

TABEL 1

Karakteristik Responden

\begin{tabular}{lcc}
\hline \multicolumn{1}{c}{ Variabel } & Jumlah & Presentasi (\%) \\
\hline Tingkat Pendidikan & & \\
\hline SMP & 1 & 2.5 \\
SMA & 31 & 77.5 \\
DIPLOMA/ & 8 & 20.0 \\
STRATA & & \\
Total & $\mathbf{4 0}$ & $\mathbf{1 0 0 . 0}$ \\
\hline Usia & & \\
\hline Beresiko & 5 & 12.5 \\
Tidak beresiko & 35 & 87.5 \\
Total & $\mathbf{4 0}$ & $\mathbf{1 0 0 . 0}$ \\
\hline Riwayat Persalinan & & 22.5 \\
\hline Belum Pernah & 9 & 47.5 \\
Normal & 19 & 30.0 \\
Operasi & 12 & $\mathbf{1 0 0 . 0}$ \\
Total & $\mathbf{4 0}$ & 22.5 \\
\hline Paritas & & 77.5 \\
\hline Primipara & 9 & $\mathbf{1 0 0 . 0}$ \\
Multipara & 31 & 87.5 \\
Total & $\mathbf{4 0}$ & $\mathbf{1 0 0 . 5}$ \\
\hline Penghasilan Suami & & \\
\hline Cukup & 35 & \\
Kurang & 5 & \\
Total & & \\
\hline
\end{tabular}

TABEL 2

Distribusi Frekuensi Tingkat Pendidikan Responden Terhadap Kecendrungan Depresi Postpartum

\begin{tabular}{|c|c|c|c|c|}
\hline \multirow{2}{*}{$\begin{array}{l}\text { Tingkat } \\
\text { Pendidikan }\end{array}$} & \multicolumn{2}{|c|}{$\begin{array}{c}\text { Depresi } \\
\text { Postpartum }\end{array}$} & \multirow[b]{2}{*}{$\mathbf{n}$} & \multirow[b]{2}{*}{$\%$} \\
\hline & $\begin{array}{c}\text { Kecen } \\
\text { Deru } \\
\text { ngan }\end{array}$ & $\begin{array}{c}\text { Tidak } \\
\text { Kecen } \\
\text { Deru } \\
\text { ngan }\end{array}$ & & \\
\hline SMP & O & 1 & 1 & 2.5 \\
\hline SMA & 16 & 15 & 31 & 77.5 \\
\hline $\begin{array}{l}\text { DIPLOMA } \\
\text { /STRATA }\end{array}$ & 4 & 4 & 8 & 20.0 \\
\hline Total & 20 & 20 & 40 & 100 \\
\hline
\end{tabular}


TABEL 3

Distribusi Frekuensi Usia Responden Terhadap Kecendrungan Depresi Postpartum

\begin{tabular}{|c|c|c|c|c|}
\hline \multirow[b]{2}{*}{ Usia } & \multicolumn{2}{|c|}{$\begin{array}{c}\text { Depresi } \\
\text { Postpartum }\end{array}$} & \multirow[b]{2}{*}{$\mathbf{n}$} & \multirow[b]{2}{*}{$\%$} \\
\hline & $\begin{array}{c}\text { Kecen } \\
\text { Deru } \\
\text { ngan }\end{array}$ & $\begin{array}{c}\text { Tidak } \\
\text { Kecen } \\
\text { derun } \\
\text { gan }\end{array}$ & & \\
\hline Beresiko & 2 & 3 & 5 & 12.5 \\
\hline $\begin{array}{l}\text { Tidak } \\
\text { beresiko }\end{array}$ & 18 & 17 & 35 & 87.5 \\
\hline Total & 20 & 20 & 40 & 100 \\
\hline
\end{tabular}

TABEL 4

Distribusi Frekuensi Riwayat Persalinan Responden Terhadap Kecendrungan Depresi Postpartum

\begin{tabular}{|c|c|c|c|c|}
\hline \multirow[b]{2}{*}{$\begin{array}{c}\text { Riwayat } \\
\text { Persalinan }\end{array}$} & \multicolumn{2}{|c|}{$\begin{array}{c}\text { Depresi } \\
\text { Postpartum }\end{array}$} & \multirow[b]{2}{*}{$\mathbf{n}$} & \multirow[b]{2}{*}{$\%$} \\
\hline & $\begin{array}{c}\text { Kecen } \\
\text { derun } \\
\text { gan }\end{array}$ & $\begin{array}{c}\text { Tidak } \\
\text { Kecen } \\
\text { derun } \\
\text { gan }\end{array}$ & & \\
\hline $\begin{array}{l}\text { Belum } \\
\text { Pernah }\end{array}$ & 6 & 3 & 9 & 22.5 \\
\hline Normal & 7 & 12 & 19 & 47,5 \\
\hline Operasi & 7 & 5 & 12 & 30 \\
\hline Total & 20 & 20 & 40 & 100 \\
\hline
\end{tabular}

TABEL 5

Distribusi paritas Responden Terhadap Kecendrungan Depresi Postpartum

\begin{tabular}{lcccc}
\hline \multirow{2}{*}{ Paritas } & \multicolumn{2}{c}{ Depresi Postpartum } & & \\
\cline { 2 - 3 } & $\begin{array}{c}\text { Kecen } \\
\text { derungan }\end{array}$ & $\begin{array}{c}\text { Tidak } \\
\text { Kecen } \\
\text { derungan }\end{array}$ & & $\%$ \\
\hline Primipara & 6 & 3 & 9 & 22.5 \\
Multipara & 14 & 17 & 31 & 77.5 \\
Total & 20 & 20 & 40 & 100 \\
\hline
\end{tabular}

TABEL 6

Distribusi Frekuensi Penghasilan Suami Responden Terhadap Kecendrungan Depresi Postpartum

\section{Depresi}

Postpartum

\begin{tabular}{lcccc}
$\begin{array}{c}\text { Pengha } \\
\text { silan Suami }\end{array}$ & $\begin{array}{c}\text { Postpartum } \\
\text { Kecen } \\
\text { derungan }\end{array}$ & $\begin{array}{c}\text { Tidak } \\
\text { Kecen } \\
\text { derungan }\end{array}$ & n & \% \\
Cukup & 17 & 18 & 34 & 87.5 \\
Kurang & 3 & 2 & 5 & 12.5 \\
Total & 20 & 20 & 40 & 100 \\
\hline
\end{tabular}

\section{Analisis Univariat}

TABEL 7

Perbedaan Jenis Persalinan terhadap Kecenderungan Depresi Postpartum

\begin{tabular}{|c|c|c|c|c|c|}
\hline \multirow{2}{*}{$\begin{array}{c}\text { Jenis } \\
\text { Persalinan }\end{array}$} & \multicolumn{2}{|c|}{ Depresi Postpartum } & \multirow[b]{2}{*}{$\mathbf{n}$} & \multirow[b]{2}{*}{$\%$} & \multirow[b]{2}{*}{$\boldsymbol{p}$} \\
\hline & $\begin{array}{c}\text { Kecen } \\
\text { derungan }\end{array}$ & $\begin{array}{c}\text { Tidak } \\
\text { Kecen } \\
\text { derungan }\end{array}$ & & & \\
\hline Normal & 8 & 12 & 20 & 50 & \\
\hline Operasi & 12 & 8 & 20 & 50 & 0.212 \\
\hline Total & 20 & 20 & 40 & 100 & \\
\hline
\end{tabular}

TABEL 8

Perbedaan Dukungan Suami Terhadap Kecendrungan Depresi Postpartum

\begin{tabular}{|c|c|c|c|c|c|}
\hline \multirow{2}{*}{$\begin{array}{c}\text { Duku } \\
\text { ngan } \\
\text { Suami }\end{array}$} & \multicolumn{2}{|c|}{$\begin{array}{c}\text { Depresi } \\
\text { Postpartum }\end{array}$} & \multirow[b]{2}{*}{$\mathbf{n}$} & \multirow[b]{2}{*}{$\%$} & \multirow[b]{2}{*}{$\boldsymbol{p}$} \\
\hline & $\begin{array}{c}\text { Kecen } \\
\text { Deru } \\
\text { ngan }\end{array}$ & $\begin{array}{c}\text { Tidak } \\
\text { Kecen } \\
\text { Deru } \\
\text { ngan } \\
\end{array}$ & & & \\
\hline $\begin{array}{l}\text { Mendu } \\
\text { kung }\end{array}$ & 2 & 18 & 20 & 50 & \\
\hline $\begin{array}{l}\text { Tidak } \\
\text { mendu } \\
\text { kung }\end{array}$ & 18 & 2 & 20 & 50 & 0.000 \\
\hline Total & 20 & 20 & 40 & 100 & \\
\hline
\end{tabular}

TABEL 9

Perbedaan Dukungan Keluarga Terhadap Kecendrungan Depresi Postpartum

\begin{tabular}{lccccc}
\multicolumn{6}{c}{ Depresi Postpartum } \\
\hline $\begin{array}{c}\text { Duku } \\
\text { ngan } \\
\text { Kelu } \\
\text { arga }\end{array}$ & $\begin{array}{c}\text { Depresi } \\
\text { Kecen } \\
\text { Deru } \\
\text { ngan }\end{array}$ & $\begin{array}{c}\text { Tidak } \\
\text { Kecen } \\
\text { Deru } \\
\text { ngan }\end{array}$ & n & $\%$ & $p$ \\
$\begin{array}{l}\text { Mendu } \\
\text { kung }\end{array}$ & 18 & 20 & 38 & 95 & \\
$\begin{array}{l}\text { Tidak } \\
\text { mendu } \\
\text { kung }\end{array}$ & 2 & 0 & 2 & 4 & 0.152 \\
Total & 20 & 20 & 40 & 100 & \\
\hline
\end{tabular}

Berdasarkan hasil analisis Mann Whitney $U$ test pada jenis persalinan menunjukan $p$ value 0,212 ( $p>$ o,05) sehinggah dapat disimpulkan bahwa Ho ditolak dan Ha diterima artinya tidak ada perbedaan jenis persalinan terhadap kecendrungan depresi post partum.

Hasil penelitian Ririn dengan judul pengaruh jenis persalinan terhadap risiko depresi postpartum pada ibu nifas menunjukan hasil ibu dengan persalinan bedah sesar memiliki peluang resiko depresi postpartum 3,7 kali lebih besar dibandingkan ibu yang persalinan pervaginam ${ }^{[10]}$.

Penelitian yang dilakukan oleh Goker di Turki yang menganalisis apakah jenis persalinan merupakan faktor resiko terjadi depresi postpartum, 
di dapatkan hasil bahwa jenis persalinan mempengaruhi terjadinya depresi postpartum serta ibu yang melakukan persalinan pervaginam memiliki resiko $27,6 \%$ untuk menderita postpartum ${ }^{[1]}$.

Hasil penelitian ini menjelaskan bahwa jenis persalinan tidak memiliki peluang resiko menimbulkan kecenderungan depresi postpartum, namun depresi post partum juga dipengaruhi oleh variabel lain.

Sejalan dengan hasil penelitian Dibaba Tingginya angka kejadian depresi baik kehamilan maupun pasca salin dipengaruhi oleh banyak hal, diantaranya adalah status ekonomi, dukungan sosial, kecemasan sebelum dan selama kehamilan, kehamilan yang tidak diinginkan serta faktor demografi yang meliputi umur, pendidikan, paritas [11].

Berdasarkan hasil analisis Mann Whitney $U$ test pada dukungan suami menunjukan $p$ value o,ooo $(p<$ o,05) sehinggah dapat disimpulkan bahwa Ho diterima dan Ha ditolak artinya ada perbedaan dukungan suami terhadap kecendrungan depresi post partum.

Hasil penelitian Winarni didapatkan ada pengaruh dukungan suami dengan kondisi psikologis ibu postpartum ${ }^{[12]}$. Hasil penelitian ini sejalan dengan penelitian Al Mutairi di Riyadh Saudi Arabia, yang menyatakan bahwa sekitar $16 \%$ ibu postpartum tidak mendapatkan dukungan suami yang cukup dari suami, sebagian besar ibu yang mengalami depresi postpartum disebabkan karena kurangnya dukungan sosial, kurangnya rasa percaya diri ${ }^{[13]}$.

Hal ini berdasarkan pernyataan Dagun bahwa dukungan seorang suami adalah hal yang memang dibutuhkan oleh istri baik saat hamil maupun ketika setelah melahirkan. Suami harus memberikan dukungan yang lebih besar kepada istrinya saat masa - masa tersebut [14]. Salah satu bentuk dukungan sosial yang dapat diberikan seorang suami kepada istrinya adalah dukungan emosional. Adanya dukungan suami akan memberikan kontribusi yang sangat berarti terhadap wanita pasca melahirkan dalam menghadapi stres yang muncul. Hal ini berdasarkan pendapat Johnson ( dalam Matson, 2011) bahwa dukungan sosial akan meningkatkan kesejahteraan psikologis individu dan kemampuan pengelolaan stres dengan menyediakan pelayanan, perawatan,kasih sayang, sumber - sumber informasi dan umpan balik yang dibutuhkan untuk menghadapi stress. Dengan demikian adanya dukungan suami akan memberikan kemampuan yang lebih kepada wanita dalam menghadapi stres yang muncul dan wanita tersebut dapat terhindar dari depresi pasca melahirkan.

Berdasarkan hasil analisis Mann Whitney $U$ test pada dukungan keluargamenunjukan $p$ value $0,152(\mathrm{p}>0,05)$ sehinggah dapat disimpulkan bahwa Ho ditolak dan Ha diterima artinya tidak ada perbedaan dukungan keluarga terhadap kecendrungan depresi post partum.
Hasil penelitian sesuai dengan teori bahwa dukungan sosial keluarga merupakan faktor yang penting yang mempengaruhi terjadinya depresi ${ }^{[15]}$.

Liberman menyatakan bahwa dengan adanya dukungan sosial yang diperoleh dari orang terdekat yaitu keluarga dapat menurungkan kecendrungan munculnya kejadian yang mengakibatkan stres, adanya interaksi dengan keluarga dapat memodifikasi atau mengubah persepsi individu pada kejadian penuh stres. Berdasarkan teori psikodinamik, stres merupakan prediktor yang baik dalam terjadinya depresi , banyak bukti yang menunjukan bahwa stres akutr dan kronis menyebabkan depresi. Salah satu kemungkinan bahwa dukungan sosial keluarga dapat meminimalkan keparahan depresi ${ }^{[16]}$.

\section{SIMPULAN DAN SARAN}

Pada bagian ini penulis merincikan kesimpulan hasil pembahasan dan analisa data dan disarankan untuk menyampaikan penelitian lanjutan untuk peneliti berikutnya.

\section{SIMPULAN}

1. Pada variabel jenis persalinan menunjukan $p$ value $0,212(p>0,05)$ artinya tidak ada perbedaan jenis persalinan terhadap kecendrungan depresi post partum.

2. Pada variabel dukungan suami menunjukan $\mathrm{p}$ value $0,000(\mathrm{p}<0,05)$ artinya ada perbedaan dukungan suami terhadap kecenderungan depresi post partum.

3. Pada variabel dukungan keluarga menunjukan $p$ value 0,152 ( $\mathrm{p}>0,05$ ) artinya tidak ada perbedaan dukungan keluarga terhadap kecenderungan depresi post partum.

4. Faktor yang paling berpengaruh terhadap kecenderungan mengalami depresi postpartum adalah dukungan suami.

\section{SARAN}

Berdasarkan hasil penelitian yang telah dilakukan, salah satu upaya yang harus dilakukan agar depresi post partum pada ibu tidak terjadi, maka peran/pendampingan suami harus lebih ditingkatkan pada ibu bukan hanya selama dia melahirkan, namun pada saat ibu menjelang hamil, melahirkan, nifas dan peran suami dalam mengasuh anak yang baru lahir. Dari hasil penelitian ini juga peneliti merekomendasikan saran - saran kepada pihak lain, sebagai berikut :

1. Bagi tempat peneliti

Agar lebih meningkatkan kampanye tentang pentingnya pendampingan suami pada proses persalinan dan nifas pada ibu.

2. Bagi Institusi

Diharapkan dapat menambah sumber-sumber informasi dan bahan bacaan mengenai nifas dan depresi postpartum khususnya mahasiswa STIKES Muhammadiyah Sidrap. 


\section{UCAPAN TERIMA KASIH}

Tim penulis mengucapkan terima kasih kepada:

1. Bapak drg. Bambang Roesmono, M.M., selaku Ketua STIKES Muhammadiyah Sidrap

2. Bapak Muhammad Tahir, SKM.,M.Kes., Bapak Drs. Abd. Hayat Fattah, M.Kes, Bapak Ishak Kenre, SKM.,M.Kes., selaku wakil ketua STIKES Muhammadiyah Sidrap.

3. Ibu Syahriani, S.ST., M. Kes selaku Anggota peneliti dalam PDP ini.

4. Kepala LPPM Eka Astuti S.Si.,M.Si dan Sekretaris STIKES Muhammadiyah Sidrap.

5. Ketua program studi pendidikan DIII Kebidanan Nurjanna, S.ST., M. Keb STIKES Muhammadiyah Sidrap.

6. Bapak dan Ibu para Dosen serta karyawan STIKES Muhammadiyah Sidrap.

7. Seluruh staf dan rekan-rekan kerja penulis di STIKES Muhammadiyah Sidrap.

8. Terkhusus untuk orang tua, keluarga, anak dan sahabat

\section{DAFTAR RUJUKAN}

[1] Goker A., et al. (2012). Postpartum Depression: Is Mode of Delivery a Risk Factor?. International Scholarly Research Network. ISRN Obstetrics and Gynecology Volume 2012, Article ID 616759, 6 pages DOI:10.5402/2012/616759. Diakses tanggal 19 Februari $2018 . \quad$ Available from: https://www.hindawi.com/journals/isrn/2012/616759/

[2] Centre for Maternal and Child Enquiries (CMACE). (2011). Savingmothers lives: reviewing maternal deaths to make motherhood safer: 2006-2008. The eighth report on confidential enquiries into maternal deaths in the United

[3] Salma. (2012). 5 Penyebab Utama Kematian Ibu di Indonesia. Majalah Kesehatan. Diakses 14 Maret 2014. Available from : http://majalahkesehatan.com.

[4] Nasution, S. (2012). Gambaran Karakteristik Demografi Penderita Sindrom Depresi Postpartum Di Rumah Sakit Umum Daerah Dr. Pirngadi Kota Medan. Universitas Sumatera Utara.

[5] Rahmi, S. (2012). Hubungan Umur dan Paritas Ibu dengan Kejadian Depresi Postpartum Pada Ibu Nifas di RSUP DR. M. Djamil Padang Tahun 2011. Diakses 12 Januari 2014.

[6] Saad R. (2017). Depresi Postpartum di Rumah Sakit Khusus Daerah Provinsi Sulawesi Selatan Tahun 2017. Program pascasarjana Universitas Muslim Indonesia. Makassar.

[7] Basri H, Zulkifli A,Abdullah T. (2014). Efektivitas psikoedukasi terhadap depresi postpartum di rsia sitti fatimah dan rsia pertiwi Makassar. Fakultas Kesehatan Masyarakat Universitas Hasanuddin. Diakses 14 Maret 2014. Available from :http://pasca.unhas.ac.id/jurnal/files/foc9cd5d46 4f7od1obb4e75f2coda11a.pdf

[8] Hakim, E. (2012). Usai Melahirkan, Ibu di Toraja Bunuh Bayinya. Liputan 6. Makassar. Available from: https://www.liputan6.com/regional/read/2511256/usaimelahirkan-ibu-di-toraja-bunuhbayinya?utm_expid=.9Z4i5ypGQeGiS7w9arwTvQ.o\&ut m_referrer=https\%3A\%2F\%2Fwww.google.co.id\%2F
[9] KompasTV. (2016). Ibu Bunuh Anak Karena Alasan Sepele. Makassar. Available from: https://www.youtube.com/watch?v=lTxbK9Je8UM

[10] Ariyanti, R., Nurdianti.D and Astuti, D. (2016). Depresi Postpartum pada Ibu Nifas. Kebidanan dan Keperawatan, 12 (2),pp. 123-128.

[11] Dibaba Y, Fantahun M, dan Hindin M.J. (2013). The Assosiation of Unwanted Pregnancy adn Sosial Support with Depressive symthoms in pregnancy : Evidance from Rural Southwestern Ethiophia. BMC Pregnancy and Childbirth. https://doi.org/10.1186/1471-2393-13-135 diakses tanggal 19 Februari 2018. Available from: https://bmcpregnancychildbirth.biomed central.com/articles/10.1186/1471- 2393-13-135

[12] Winarni, L. M., Winarni E and Ikhlasiah, M . (2017). Pengaruh Dukungan Suami dan Bounding Attachemnet dengan Kondisi Psikologi Ibu Postpartum di SDUD Kabupaten Tangerang. 305 (2), pp 1 -11.

[13] Almutairi A.F. Et al. (2017). Impact of help-seeking behavior and partner support on postpartum depression among Saudi women. Neuropsychiatric Disease and Treatment. DOI:10.2147/NDT.S135680. Available from: https://www.ncbi.nlm.nih.gov/pubmed/28790828

[14] Dagun, S.M. (2002). Psikologi keluarga. Jakarta: Rineka Cipta

[15] Maryam, R. S., Ekasari, M. F., Rosidawati, Jubaedi, A. \& Batubara, I. (2008). Mengenal Usia Lanjutdan Perawatannya. Jakarta: SalembaMedika

\section{PROFIL PENULIS UTAMA}

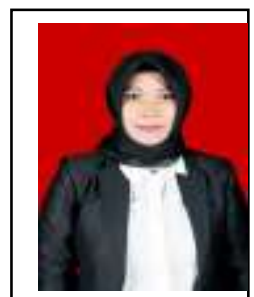

Nama : Wilda Rezki Pratiwi, S.ST., M. Kes Alamat : Panincong , Kecamatan Marioriawa Kab. Soppeng Jabatan Fungsional : Asisten Ahli No Hp : :082346652133 Riwayat pendidikan :

1. SD Negeri 62 Lompo Panincong Kabupaten Soppeng

2. SMP Negeri 03 Panincong Kabupaten Soppeng

3. SMA Negeri 01 Donri - Donri Kabupaten Soppeng

4. Dipoloma Tiga kebidanan di Akbid Muhammadiyah Makassar

5. DIV Bidan Pendidik STIKES Mega Rezky Makassar

6. S2 Konsentrasi Kesehatan Reproduksi di Universitas Muslim Indonesia ( UMI ) di Makassar 